\title{
Manipulation in Drama translation: A case study of Waiting for Godot
}

Vasheghani Farahani, Mehrdad

Islamic Azad University; Science \& Research Branch, Tehran, Iran (Mehrdadfarahani1365@gmail.com)

Arbabi, Maryam

Islamic Azad University, Central Branch,Tehran, Iran (arbabi22@gmail.com)

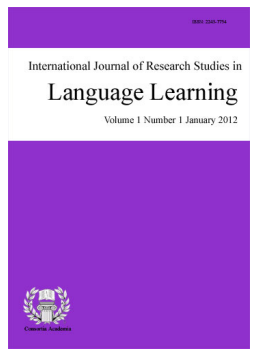

ISSN: 2243-7754 Online ISSN: 2243-7762

OPEN ACCESS

\section{Abstract}

The present case study attempted to probe into one of most appealing translations of "Waiting for Godot", from English into Persian, which was manipulated in the process of translation and to investigate the manipulative strategies and to identify the most frequent one in them. The corpus selected for this study is a bilingual parallel corpus comprising an English-Persian translation of the originally French play called Waiting for Godot, by Samuel Beckett. The English component of the corpus was translated by Beckett himself. The Persian component, however, was translated by Ali-akbar Alizadeh. The present research was limited to 'manipulation as distortion' category of Dukate's (2007) general manipulation typology. As the data demonstrated, "substitution" was the strategy most-frequently applied by the translator when translating "Waiting for Godot"; covering 142 items. The next frequent strategy was "addition"; covering 49 cases. "Omission" ranked next to "addition", as the third most-frequently applied strategy; 23 items had been omitted.

Keywords: drama translation; manipulation; manipulation schools; translation strategies 


\section{Manipulation in Drama translation: A case study of Waiting for Godot}

\section{Introduction}

According to Mafizadeh (2007) Drama translation is probably of the most problematic and neglected issues in the domain of translation studies. Less has been written on problems of translating plays than on translating any other text type. Like almost any other text, theatrical texts are inevitably decoded in the process of translating. "Many drama writers like Chekhov, thought that they could have stopped their plays from being translated outside their countries, since the readers did not have access to specifications in their target texts" (Bassnet \& Lefevere, 1998, p. 91).

Manipulation School originated from the idea proposed by Hermans (1985) that "all translations have some amount of manipulation for some reason" (p. 11). Manipulation scholars demonstrated that

translations rather than being secondary and derivative, were instead one of the primary literary tools that larger social institutions - educational systems, arts councils, publishing firms, and even governments - had at their disposal to manipulate a given society in order to construct the kind of culture desired. (Tymoczko \& Gentzler, 2002, p. 29)

The present research is based on and uses the definition of manipulation proposed by Dukate (2007). She defines manipulation as:

The translator understanding of a text which eventuates in adaptation of the message in target reader, in terms of cultural, ideological, linguistic and literary mismatches among the cultures is done by human manipulation and this entails some impact of individual factors (Dukate 2007, p.

11)

\subsection{Statement of the Problem}

According to Mafizadeh (2007), Theater is a well-known way of sending social, religious and political beliefs to the audience. Like other nations, Iranian people are also interested in dramas and theatrical productions. A great deal of foreign dramas have been translated and performed in Iran. However, it seems that Iran's contemporary translated theatrical texts are usually inclined toward localization and a consequent distortion of English as the hegemonic language. Over the last years, with the growing interest in drama translation, the number of readers has also increased in this country. It seems that in the process of drama translation, the original version of the theater text undergoes fundamental changes to the extent that usually the original concept is either lost or reinterpreted. Factors such as the translator's ideological background and the society's dominant ideology affect the outcome of drama translation. In some cases, a work of drama may get retranslated by several translators in order to adapt the translated version to the norms and cultural patters at the time of the translation.

\subsection{Research Questions}

According to Dukate's (2007) manipulation typology, what manipulation strategies are applied in the Persian translation of the play "Waiting for Godot"? Which of these manipulation strategies is the most frequent one? What might be the implications of such preference in drama translation?

\section{Review of the Related Literature}

In order to have a full account of what has already been done in this area of research, it seems important to have a survey over the view- points of different scholars towards manipulation school and also some theoretical 
issues related to the current study.

\subsection{Translation Theory through History}

According to Snell-Hornby (1990) "translation theory puts emphasis on literary translation and the age-old dichotomy of "faithful" versus "free" translation. The study of translation was a part of the discipline known as "Comparative Literature" (p. 79). Under the influence of machine translation in the 1950s, Nida (as cited in Snell-Hornby, 1990) introduced "science of translating" to the field of translation; saying that this major was defined as a branch of Applied Linguistics for quite a long time. Indeed, translation was considered as linguistic transcoding and then the illusion of equivalence appeared.

During the 1950s and 1960s, a formalist trend impacted on literary studies and in these studies, the emphasis was put on linguistic and stylistic specifications of literary texts (Holmes, Lambert, \& van den Broek, 1978). With the developments of translation studies in the 1970s and 1980s, functionalist and communicative translation theories "moved translations from a statistic linguistic phenomenon to being considered as an act of intercultural communication" (Munday, 2008, p. 87). Dukāte (2007) says that the functional approaches look at translation from cultural and social perspectives and this context will determine the meaning in the receiving culture.

\subsection{Polysystem Theory of Translation}

Polysystem Theory introduced by Even-Zohar in the 1970s was another reaction to the static prescriptive model of translation. Even-Zohar mostly focuses on the role that literary texts have in poly system of a culture and on the role it plays in translation studies (Baker \& Saldanha, 1998). Unlike previous models which classified translation as secondary systems, Even-Zohar (2000) sees translated literature as a dynamic structure which functions in the social, literary and historical structure of the receiving culture and puts emphasis on the role that translated literature has in the literary polysystem. He (2000) outlines three social situations in which translation would maintain a primary position:

$>\quad$ When a literature is "young", or in the process of being established;

$>\quad$ When a literature is "peripheral" or "weak" or both; and

$>$ When a literature is experiencing a "crisis" or turning point.

In the two first cases, translation fulfills the need of a young literature to use its new language for as many different kinds of writing as possible. In the third situation, established literary models no longer simulate the new generation of writers, who turn elsewhere for ideas and forms:

The position of translated literature within the polysystem conditions the translation strategy. If it is primary, the translators are not constrained to use target literature models and they are able to break conventions. On the other hand, if translated literature is secondary, translators tend to use existing target culture models for the target text and produce more "non-adequate" translation (Even-Zohar, 2000, p. 196).

\subsection{Descriptive Translation Studies (DTS)}

Polysystem theory led to developments in descriptive translation studies. Holmes (1972) views translation studies as a newly stablished trend which surrounds encompasses the structures, objectives and methods of the natural sciences. He (as cited in Shuttleworth \& Cowie, 1997) specified the aim of DTS as to describe the phenomena of translating and translation(s) as they manifest themselves in the world of our experience.

Toury (1980/1995), mainly influenced by Even-Zohar's Polysystem and brought about major changes and 
Vasheghani Farahani, M., \& Arbabi, M.

developments in this field of study. He argues that translations are "facts of one system only: the target system" (1995, as cited in Shuttleworth \& Cowie, 1997, p. 39). As a matter of fact, Toury's approach is totally target-oriented; whilst other approaches believed in TT as a recontextualisation of ST, Toury draws the attention to focus on the TT and its position in the target culture. He argues that the target text's specifications cannot be determined by the ST culture or by the translational processes as by the constellation of the target culture itself (Toury, 1984, as cited in Shuttleworth \& Cowie, 1997).

According to Baker and Saldanha (2009), Toury and other pioneers of the descriptive approach, such as Hermans and Lambert, were highly important in putting translation studies on a firm footing as an academic discipline. The descriptivist approach also laid the foundations for further developments, notably approaches that are sometimes referred to as the "cultural turn" in translation studies and which foreground the role of translation as a cultural vector.

\subsection{Cultural Turn in Translation Studies}

The cultural turn started in the 1990s and brought about a number of approaches / trends which viewed translation in terms of cultural. Indeed, translation was seen from cultural systems and ideological perspectives which emerge from systems (Baker \& Saldanha, 2009). This implied that translation was recognized not only as part of the language, but in relation with languages in culture, and that differences between languages are not only found in the linguistic systems, but in culture. In the introduction of Translation, History and Culture, Bassnett and Lefevere (1990) offered a new approach to the study of translation, the "cultural turn" in Translation Studies, namely that translation is studied within a broader political and cultural context. Studies of translation undertaken within these frameworks may remain descriptive. This cultural turn can be regarded as the most important shift in Translation Studies; meaning that neither the word, nor the text are not into the focus, rather it is the culture which becomes as the translation unit (Bassnett \& Lefevere, 1990). They argue that translation plays a major role in shaping literary systems and the translator is involved in complex power negotiations.

\subsection{Manipulation School of Translation Studies}

Dukāte (2007) mentions that the Manipulation School introduces a way to translation as manipulation or to put it differently, to paraphrase the text for the receivers in accordance with target text. Tymoczko and Gentzler (2002) believes translation not as secondary, but as a primarily position in larger social institutes, educational systems, arts associations, publishing companies and governments that had their role in manipulating the society. As Dukāte argues:

The members of manipulation school are mostly researchers from such countries as Belgium, the Netherlands, the former Czechoslovakia and Israel and some of its most well-known members are Holmes, Lefevere, Lambert, Hermans, Bassnett, Even-Zohar, and Toury. These groups and scholars were vehemently influenced by Even-Zohar's Polysystem Theory. They have also been known under other names such as, Translation Studies, the Low Countries Group, the Descriptive, Empirical or Systemic School, the Polysystem Approach, the Tel-Aviv-Lueven Axis (Dukāte, 2007, p. 39).

Dukāte (2007) claims that the most well-known name of this group is the Descriptive Translation Studies; they describe the nature of this school of thought. The name "manipulation school" arose because of the group "s attitude toward the manipulative nature of translation; particularly, in a provocative statement, Hermans (1985) claims that from the target perspective "all translation implies a degree of manipulation of the source text for a certain purpose" (p. 11). This purpose is linked to the operation of ideology, patronage and poetics (Lefevere 1992). Scholars of Manipulation School, instead of being faithful copies of the original, focused on revealing how this claim has happened. Herman (1985) describes, the members of the Manipulation School all believe that 
literature is a complex and dynamic system and that there should be a permanent interplay between theoretical and practical areas. This approach is descriptive, target oriented, functional and systematic in nature.

\subsection{The role of Ideology and Power Relations in Translation}

As mentioned previously, the influence of ideology and power relations on translation practice has drawn great attention from relevant scholars since the cultural turn in Translation Studies in the 1990s. To emphasis the salient role of power and agency in current researches in the domain of translation studies, Gentzler and Tymoczko (2002) proposed the term "power turn". They claimed that "cultural turn in translation studies has become the power turn which questions of power brought to the fore in discussions of both translation history and strategies for translation" (Tymoczko \& Gentzler, 2002, p. xiii). They explained that translation cannot be the mere act of faithful reproduction of message; instead, it is an intended and a conscious act of selection, assemblage, structuration and fabrication, refusal of information and the creation of message. Thus, translator like creative writers and publications emerge as powerful actors which shape knowledge and culture (Tymoczko \& Gentzler 2002).

Lefevere explains that "rewriters adopt, manipulate the original they work with to some extent, usually to make them fit in with the dominant, or one of the dominant ideological and poetological currents of their time" (Lefevere, 1992, p. 8). He claims that rewriters/translators are, to some extent, are like traitors; who destroy the target message towards the target text and culture (Lefevere, 1992). According to him, translation is mainly controlled by three factors, which are: professionals within the literary system, patronage outside the literary system and the dominant poetics.

Indeed, translation as a communicative event can never be studied without taking its situational and socio-cultural context in to account. Schäffner (as cited in Calzada-perez, 2003) mentioned, both texts, ST and TT, serve as windows onto ideologies and political power relations in the contemporary world. Calzada-pérez (2003) believes that ideology "gradually becomes every day, common thinking" and "...the more naturalize it is, the more successful it becomes amongst its subjugated citizens" (p. 4). She states that recent definitions of ideology are linked with the concepts of power relations and domination. As she (2003) argues, sometimes ideology is viewed in more positive sense as a vehicle to promote or legitimate interests of a particular social group. She goes on to explain that any translation is ideological because the choice of the source text and the use according to which the translation is formed, are all determined by the interests, aims, and objectives of social agents, even the preference of one word instead of another, as a part of decision-making of the translator is also ideology-reflected. At the lexical level, as another instance, we can refer to the use of passive instead of active voice. The topic of the text, the genre, and the communicative purpose are also prominent (Calzada-pérez 2003, $23)$.

\section{Manipulation School of Translation Studies}

As Dukāte (2007) mentions, "the Manipulation School represents an approach to translation as manipulation or more precisely as rewriting of texts for a specific target audience in conformity with target language norms and under various constraints."(p. 39). Considering this approach, translations are not regarded as a secondary or derivative activity, rather they are considered as one of the primary literary tools that can extend social-educational systems, arts councils, publishing companies and even governments had their disposal to manipulate the society in order to construct the kind of culture they had intended (Tymoczko \& Gentzler 2002, p. xiii).

According to Dukāte (2007), the members of manipulation school are mostly scholars from Belgium, the Netherlands, the former Czechoslovakia and Israel. Some of its most prominent members are Holmes, Lefevere, Lambert, Hermans, Bassnett, Even-Zohar, and Toury. This group was heavily influenced by Even-Zohar's Polysystem Theory. They have also been known under other names such as, "Translation Studies, the Low 
Vasheghani Farahani, M., \& Arbabi, M.

Countries Group, the Descriptive, Empirical or Systemic School, the Polysystem Approach, the Tel-Aviv-Lueven Axis" (Dukāte 2007, p. 39). Dukāte (2007) claims that the most common name of this group is "The Descriptive Translation Studies", since it most precisely describes the essence of this school of thought. The Manipulation School arose first as a word-play deriving from the collection of essays called The Manipulation of Literature. The name "manipulation school" arose because of the group's attitude toward the manipulative nature of translation; particularly, in a provocative statement. Hermans (1985) claims that from the target perspective "all translation implies a degree of manipulation of the source text for a certain purpose" (p. 11). This purpose is linked to the operation of ideology, patronage and poetics (Lefevere, 1992). Scholars of Manipulation School, instead of being faithful copies of the original, focused on revealing how this claim has happened.

As Hermans describes

The members of the Manipulation School have shared a view of literature as a complex dynamic system; a conviction that requires an everlasting interplay between theoretical models and practical case studies; an approach towards literary translation which is descriptive, target text oriented, functional and systemic oriented (Hermans 1985, pp. 10-11).

Dukāte (2007) mentions that based on the group's views all translation might be manipulative — because of the factors in place and processes at work in three translation "related stages, the pre-production stage, the production stage and the post-production stage" (p. 5). She (2007) goes on to explain that in the first stage relating to the selection of a text to be translated, "there are certain agents, certain power at the source or the target pole, who make decisions on which works to translate and how." (p. 6) According to her (2007) in the next stage, i.e. production stage, the translator works under various constraints and receives certain guidelines, indications and hints about the way a certain text should be translated. In this stage, there are also "various objectives (e.g. language-related) and subjective (e.g. ideological and psychological) factors" which have direct impact on the translator's work.

\subsection{Translation and Manipulation}

Generally, there are different terms used by various scholars referring to the issue of difference between ST and TT. For example Catford, Poppvič, Toury, and van Leuven Zwart (as cited in Dukāte 2007) speak about "shift" in translation as the result of the translators' attempt to comprehend and faithfully reproduce the source text. House (1997) speaks about the application of "a cultural filter" to overcome the cultural gap. Lefevere (1992) speaks about "rewriting" for this type of text handling. All of the above terms, i.e., shifts, cultural filters, rewriting or manipulation could be perceived as the same phenomenon; translator's handling of a text as a result of which the text becomes adapted for the target reader. However, each term highlights different aspects of translation. It seems that the term "manipulation" is wider than any of the above- mentioned terms and mainly focuses on cultural and ideological aspects of translation.

Dukāte (2007) believes that there are two ways in detecting manipulation in specific contexts. First, it can be seen as an action and secondly, it can be seen as a strategy which is used to make people believe or do some certain things. In the field of Translation Studies, the term manipulation has a variety of meanings. Dukāte (2007) claims that conventionally, the word manipulation refers to conscious and devious strategies used by people to mislead and influence others. However, she (2007) argues that in translation, like other fields such as finance, computer or medical sciences, manipulation refers to distortion and to improvement.

Chrisafulli, (as cited in Kramania, 2004) says that the term manipulation is understood in two ways. It can be understood as something negative and as the signs of translator's ideological influences in target text. Dukāte (2007) on the other hand, believes manipulation as positive phenomena, because the translator tries to make it closer to target text. Katan (1999) thinks that manipulation is part and parcel of a translation. He believes that any translation requires manipulation. He also claims that faithful translations can be as devious as or even more devious than allegedly free translations. He considers distortion as a type of manipulation and believes that 
"distortion can occur through a faithful, literal translation and by making explicit what was originally implicit. According to him, distortion in itself is neither good nor bad.

\subsection{Reasons for Manipulation}

Manipulation School maintains that "all translation implies a degree of manipulation of the source text for a certain purpose" (Hermans, 1985, p. 11).Yet, what exactly induces translators to manipulate source texts? In what follows, some reasons will be enumerated. Lefevere (1992) believes that translation can never refrain itself from the political and literary power relations of the target structures and culture. More often than not, if translators want their work to be published and well-received at the target pole, they cannot disregard those constraints. Dukate (2007) points out that manipulation, according to the views of this school, is the result of both the hybrid structure of translation and to the power relations within the polysystem or between the systems of different cultures.

Farahzad (1998) differentiates between two types of manipulation, as conscious and unconscious, and accordingly describes two types of processes which lead to manipulation of texts in translation:

The conscious process eventuates in intended manipulation carried out by the translator because of such factors as social, political and etc. The unconscious manipulation is rather a psychological process and occurs due to the influence of psychological factors. (Farahzad, 1999, p. 156)

According to Dukate (2007) the reasons why unconscious manipulation occurs can also be explained by referring to Toury's (1995) translation laws. The law of growing standardization states that "in translation, textual relations obtaining in the original are often modified, sometimes to the point of being totally ignored, in favor of habitual options offered by a target repertoire" (p. 268). Toury (1995) explains that the translator's behavior is influenced by a multitude of variables such as biological and bilingual age, or previous experience in translation of different kinds and for different purposes. Another influential factor, according to Toury, is the position of translation within a particular culture. Thus,"the more peripheral this status, the more translation will accommodate itself to established models and repertoires" (pp. 270-271).

Toury's (1995) second translation law, the law of interference, which states that "in translation, phenomena pertaining to the make-up of the source text tend to be transferred to the target text" (p. 275), also might be used to explain why manipulation occurs. Toury explains that the everlasting tension between the desire to produce a translation closely to the original text and the intention to comply with the preponderant necessities for fluent, native-sounding texts can eventuate in manipulation, or in other words positioning the translation between acceptability and adequacy in a sense that "the more the make-up of a text is taken as a factor in the formulation of its translation, the more the target text can be expected to show traces of interference" (Toury, 1995, p. 276).

\section{Methodology}

\subsection{The Design of the Study}

This research of this study is of descriptive, non-experimental and comparative in nature and falls into the category of "Descriptive Translation Studies" (DTS) as developed by Toury (1995) and takes advantage of a bilingual parallel corpus. Being corpus-based, this study tries to explore the manipulative aspects of translated play “Waiting for Godot”.

\subsection{The Corpus of the Study}

The corpus selected for this study was a parallel corpus comprising an English-Persian translation of the originally French play called Waiting for Godot, by Samuel Beckett. The English part of the corpus was 
Vasheghani Farahani, M., \& Arbabi, M.

translated by Beckett himself and the Persian component, by Ali-akbar_Alizadeh.

\subsection{Theoretical Framework}

The theoretical framework adopted for this study is based on Dukate's (2007) general manipulation typology. She puts the examples of manipulation under three major categories of a) Manipulation as improvement b) Manipulation as distortion and c) Manipulation as handling. Hethen (2000) defines the effective manipulative strategies for each category.

The present research will be limited to 'manipulation as distortion' category and its relative strategies because English is generally known as the hegemonic language while Persian is known as an inferior language. The fact that English is the language of hegemony could be inferred from Dukate's (2007) argumentation that "the labels attached to manipulation, i.e. 'manipulation as distortion' or 'manipulation as improvement', depend on the person who evaluates the instances of manipulation. According to Dukate's second category, manipulation may lead to the distortion of a literary work. The present study, aims at investigating these distortive strategies in drama translation as part of literature. According to Dukate (2007), the distortive aspect of manipulation in translation covers omission, addition, substitution and attenuation. She defines distortion as the changing of meaning or purpose of something into something which does not correspond to the truth. In case of translation, it is the changing of the input information, being the content or the meaning or the message of the text in a way that makes it different from the original or may lead to misinterpretation. This can be done in various ways for example by adding or omitting parts of the message, changing the tone or meaning of the original.

\subsection{Procedure}

The data consisted of the dialogues of the play and their Persian translated version. In the first phase, the original English sentences were compared and contrasted with their corresponding Persian translations in parallel to reveal the existing manipulations. In the second phase, manipulative strategies were determined based on Dukate's (2007) proposed strategies to see if the original text had been manipulated through translation. Then the items were tabulated for further analysis mainly to find out the most frequent strategy applied in the translation of the play under study.

\subsection{Data Analysis}

Having tabulated the data, a quantitative analysis was done for each table separately and then the same is conducted for each category as whole. Eventually the frequency of each manipulation type as well as each manipulative strategy were presented separately in numbers and percentages and are demonstrated in the form of charts and figures. Finally, the interpretations of the chart and research findings were presented.

\section{Research Findings}

The present study sought to investigate the manipulative strategies and the types of manipulation employed in the process of Drama translation and subsequently decide on the strategy with the highest distribution. As mentioned, Dukate's (2007) typology of manipulation was adopted for this study. However, the researcher decided to focus on the distortive aspect of manipulation in translation of Waiting for Godot which covers the strategies; namely as Omission, Addition, Substitution, and Attenuation.

As the data represents, "substitution" was the strategy most-frequently applied by the translator when translating Waiting for Godot covering 142 items; compromising $65.13 \%$ of the total occurrences. The next frequent strategy was "addition"; that is to say, out of 218 items under study, 49 cases were addition; compromising $22.47 \%$ of the total occurrences. "Omission" ranked next to "addition" as the third most-frequently applied strategy; 23 items were omitted for different reason; compromising $10.55 \%$ of the total 
occurrences. And finally 4 items were attenuated in order to suit Iranian norms; compromising $1.88 \%$ of the total occurrences.

\section{Results and Discussion}

Considering the research questions of the study, as the results revealed, "substitution" was the most frequently used strategy in the examined corpus with the majority of the cases (142 out of the total 218) and the highest percentage among all the manipulative strategies $(65.13 \%)$. It seems that in order to adapt a drama to a foreign society's linguistic and cultural standards many elements of the original drama has to be substituted with more relevant items to bring it closer to the target community's cultural values. The case is especially true about plays since they are exposed to the common audience in every society and modifications are needed to fill the cultural and linguistic gaps between the two communities. However, substitutions are not restricted to culturally or ideologically unsuitable concepts. Whenever a concept is seen to be unsuitable in a given context it may be substituted with a more appropriate one. Therefore, the great number of substitutions in the examined play reveals the translator's attempt to domesticate it using more familiar and suitable elements for the target viewers. Based on the results of this study substitutions were mainly utilized for two specific goals: a) explicitation, b) domestication.

Throughout analyzing the data, substitution was used as one of the major means of explicitation and domestication of unfamiliar concepts. Explicitation is a phenomenon, which "frequently leads to the target text stating ST information in a more explicit form than the original" (Shuttleworth \& Cowie, 1997, as cited in Dukate, 2007). Although it is usually accomplished through expansion, adding some elements to the original item, in most of the cases found in the corpus appeared in the form of substitution. It is considered to be one of the most typical features of translation and it is labeled by Toury as one of the universals of translation (1980, as cited in Dukate, 2007). Although it is defined under the category of "manipulation as distortion", this element basically improves the comprehensibility of the ST because from the point of view of Target Audience the fact that the message is more clear than the original is usually perceived as improvement but considering the ST original message, any measure that makes a TT distant from the original one is recognized as a distortive exercise.

\subsection{Discussion}

The current case study sought to explore the manipulation strategies in Waiting for Godot translation and to find out the most frequent ones. To do so, the data that consisted of the dialogues of the play and their Persian translated version were selected. At first, the original English sentences were compared with their corresponding Persian translations in parallel to reveal the existing manipulations. Then, manipulative strategies were determined based on Dukate's (2007) proposed strategies to see if the original text had been manipulated through translation or not. As the data showed, substitution was the most frequently used strategy in the process of translation. In line with this finding, a study which had been conducted by Misaghy ( 2014) on manipulative strategies in three novel Kite Runner, Animal Farm, Scarlett Letter, showed that substitution was the most Frequent type of manipulative strategies and attenuation was the least one. Also, a study which had been conducted in the field of audiovisual Translation by Ghasemi (2012) showed that in the dubbed version of the Prison Break substitution was the most frequent type of manipulative strategies and deletion was the least one. However, according to a study which had been done by Salehi (2001) on manipulative strategies in two other English novel The Gad Fly and Darkness at Noon before and after Islamic Revolution showed that deletion was the most frequent type of manipulative Strategies and addition was the least one.

\section{Conclusion and Implications}

Within the limits set by the scope of this case study, the present research made an attempt to describe the manipulative nature of translating dramas, in this case, the play, "Waiting for Godot". Although the results 
cannot be over-generalized on the basis of a single play, the finding can still be seen as useful information about dealing with the linguistic and cultural differences in the process of translating plays as well as being a possible basis for more profound future studies.

Based on the results, it was concluded that translations may have a double connection with the source language and culture on the one hand and the target language on the other hand. The great number of substitutions and the high frequency of manipulations in the play examined, revealed the translator's attempt to localize Waiting for Godot for the target readers as much as possible. In this case, explicitation and domestication were formerly described to be the major mediums of adapting the unknown elements of the foreign play to Persian readers' culture and habits. This was carried out through a series of substitutions of unfamiliar and strange elements with more familiar and local items in the target culture so as to make the translation more comprehensible and enjoyable, which is a crucial factor for the target readers.

"Addition" technique as the second most common strategy was mostly done with the aim of clarifying an unfamiliar element for the Persian readers. The expansions helped the translator with the unknown concepts throughout translation. Apart from the unidentified elements, in several cases by adding one word or two, the translator had tried to smooth the flow of the speech while making it sound more natural to the target reader. However, some of the items were merely added to accentuate a certain circumstance; there were mainly synonyms repeated one after the other by the translator seemingly to highlight some point. "Omission" as the third commonly used strategy was carried out mainly to overcome linguistic differences. Most of the long sentences had been shortened and some sentences had been turned into single words due to the structural differences between English and Persian structures. Moreover, in a few cases, omission had been applied to the entire sentences; meaning that the whole sentence had not been translated at all. The least frequent strategy in this examination was "attenuation". The elements in this category mostly covered words of aggressiveness, bad tempers, curses; they were almost mitigated by the translator.

On the whole, it can be concluded that no work of art is translated in vacuum and every translator has to conform to the governing norms of the target culture and target language. The same goes with the translated play under study. Waiting for Godot, due to its cultural and social significance as well as its public appeal in the source and target culture, has also undergone certain manipulative actions. The translator may consciously and subconsciously use manipulative strategies to impose certain conscious or subconscious ideological, cultural and linguistic implications. In fact, it is the translator who may either simply reproduces the target text, or may totally recreate the source text in the target language. According to the findings, the translator was more inclined toward substituting elements than adding or omitting them.

This study provides the students of translation with instances of how the translator's choice in the translating process of a play can draw the translation into a desired direction and to what extent manipulative measures are usually involved in drama translating. Also, the conducted study can prepare the ground for those who wish to numerically and statically delve into the analysis of manipulation strategies in translation process. Also, the findings of the current study can be useful for translation critiques and for those who teach translation criticism. They can see how manipulation strategies can have impacts on play translation and how critiques should evaluate plays translation in terms of manipulation strategies. They can also, critique translations in terms of different manipulation strategies and specify their frequency. Furthermore, the finding of the present study can be used in translation teaching and translation classes. The teachers can provide students with different types of manipulation and teach them the way plays can be manipulated based on the norms and regulations of the target text.

\subsection{Limitation of the study}

As with any research project, the current study faced up with a number of limitations, some of which could have influenced the findings and confined the generalizability of the results. Being aware of the limitations of the 
research might pave the way for conducting more research in future, what follow is the limitations over which the researcher had little or no control. The present study was based on manipulation as distortion' category of Dukate's (2007) general manipulation typology. It could be better to conduct the research based on other categories, as well. Also, the current study was based on a case study and no comparative study was conducted. The last but by no means the least limitation mentioned here is that since, the scope of the present study falls into descriptive translation studies, the researchers had no control over the translator or the translation process.

\subsection{Suggestions for Further Research}

In what follows, some of the issues that need more investigation in the domain of manipulation and drama translation will be presented.

$>$ Exploring the relationship between manipulation and equivalent effect in the case of literary translation.

$>\quad$ Studying other categories of Dukate's typology in drama translation.

$>\quad$ Studying manipulative strategies in dubbed and subtitled movies.

$>\quad$ Studying manipulation in English short stories after the Islamic Revolution.

\section{References}

Baker, M., \& Saldanha, G. (Eds.) (2009). Routledge encyclopedia of translation studies (2 ${ }^{\text {nd }}$ ed.). London: Routledge.

Bassnett, S., \& Lefevere, A. (2001).Constructing cultures: Essays on literary translation. Shanghai: Shanghai Foreign Language Education Press.

Bassnett, S., \& Lefevere, A. (Eds.). (1990). Translation, history and culture. London: Cassell.

Dukāte, A. (2007). Manipulation as a specific phenomenon in translation and interpreting. Doctoral dissertation, university of Latvia. Retrieved from http://www.luis.lanet.lv/pls/luj.fprnt_1=1\&fn-F17061/Aiga\%20Dukate@202007.pdf

Even-Zohar, I. (1990). Polysystem studies. Special Issue of Poetics Today, 11(1).

Even-Zohar, I. (2000). The position of translated literature within the literary polysystems. In L. Venuti (Ed.), The translation studies reader (pp.192-197). London : Routledge.

Farahzad, F. (1998). A Gestalt approach to manipulation in translation. Perspectives: Studies in Translatology, 6(2), 153-233. http://dx.doi.org/10.1080/0907676X.1998.9961332

Hermans, T. (1985). The manipulation of literature: Studies in literary translation ( ${ }^{\text {nd }}$ ed.). London and Sydney: Croom Helm.

Holmes, J. S. (1972) .The name and nature of translation studies. In J. S. Holmes (Ed.), Translated! Papers on literary translation and translation studies (pp. 67-80). Amsterdam: Rodopi.

Holmes, J. S. Lambert, J., \& Van den Broek, R. (1978). Literature and translation: New perspectives in literary studies with a basic bibliography of books on translation studies $\left(4^{\text {th }} \mathrm{ed}\right.$.). Leuven: Acco.

Katan, D. (1999). Translating cultures: An introduction for translators, interpreters and mediators. Manchester UK: St. Jerome Publishing.

Kramina, A. (2004). Translation as manipulation: Causes and consequences, opinions and attitudes. Available from http://www.Kalbos.1t/zurnalai/06_numeris/06.pdf

Lefevere, A. (1992). Translation, rewriting and the manipulation of the literary fame. London and New York: Routledge.

Lefevere, A. (1996). Translation and canon formation: Nine decades of drama in the United States. In R. Alvarez \& M. C. Vidal (Eds.), Translation, power, subversion (pp. 138-155). Clevedon: Multilingual Matters.

Mafizadeh, B. (2007). Contemporary Iranian theater translation and cultural relocation: A cultural approach to 
Vasheghani Farahani, M., \& Arbabi, M.

transfer of Persian theatrical texts onto English stages through translation. University of London.

Misaghi, S. (2014). The manipulative strategies in translation of three English novels based on Dukate theoretical framework. Unpublished Thesis, Tehran, Islamic Azad University, Central Tehran Branch.

Munday, J. (2008). Introducing translation studies: Theories and applications. London \& New York: Routledge.

Shuttleworth, M., \& Cowie, M. (1997). Dictionary of translation studies. Manchester: St Jerome.

Snell-Hornby, M. (1990). Linguistic transcoding or cultural transfer? A critique of translation theory in Germany. In S. Bassnett \& A. Lefevere (Eds.), Translation, history, and culture (pp. 79-86). London: Pinter.

Toury, G. (1995). Descriptive translation studies and beyond. Amsterdam: John Benjamins. http://dx.doi.org/10.1075/btl.4

Tymoczko, M., \& Gentzler, E. (Eds.) (2002). Translation and power. Amberst, Boston: University of Msssachusetts Press. 